О. И. Гамали

\title{
СЕМАНТИКА НАИМЕНОВАНИЙ ПИЩЕВЫХ ПРОДУКТОВ В РУССКИХ ФРАЗЕОЛОГИЗМАХ
}

\author{
Гамалі О. І. Семантика найменувань харчових продуктів у російських \\ фразеологізмах. \\ У статті розглянуто семантичні трансформації компонентів - назв харчових \\ продуктів у складі російських фразеологізмів. Виявлено найчастіше згадувані назви \\ харчових продуктів, основні мотиваційні ознаки для семантичних трансформацій, а \\ також найбільш типові - конкретні та абстрактні - контекстуальні значення \\ трансформованих компонентів. 3'ясовано, що семантично трансформуються \\ здебільшого назви традиційних для російської кухні страв. \\ Ключові слова: національно-мовна картина світу, фразеологія, паремія, \\ семантичні трансформації, назви харчових продуктів.
}

Гамали О. И. Семантика наименований пищевых продуктов в русских фразеологизмах.

В статье рассмотрены семантические трансформации компонентов наименований пищевых продуктов в составе русских фразеологизмов. Выявлены наиболее часто упоминаемые названия пищевых продуктов, основные мотивационные признаки для семантических трансформаций, а также наиболее типичные - конкретные и абстрактные - контекстуальные значения трансформированных компонентов. Установлено, что семантически трансформируются преимущественно наименования традиционных для русской кухни продуктов.

Ключевые слова: национально-языковая картина мира, фразеология, паремия, 
семантические трансформации, наименования пищевых продуктов.

Hamali O. I. The semantic of names of food in Russian phraseology.

The article deals with the semantic transformation of names of food as idiom's components in Russian phraseology and paroemia discourse.

The actuality of the work is determined by anthropocentrism of modern linguistics, interest to interrelation between language and culture, to modelling of national language world views. Specific representatives of the situations are the means of reflection of everyday consciousness in the image-bearing language world view. The images of the dishes are a part of the national world view. The purpose of the work is to describe the specifics of contents and semantic transformation of components - names of food products in Russian phraseological units, including paroemias. Based on 1,000 phraseological contexts of the Russian language, the phraseological "menu" has been created that demonstrates the variety of traditional cuisine: bakery products, drinks, snacks, spices, soups, ritual and holiday dishes, farinaceous, dairy products, desserts. The process involved identification of the most frequent denominations, description of the semantics of the denominations хлеб ("bread"), щуи ("shchi”), каша ("porridge"), молоко ("milk"), масло ("butter"), яйu̧о ("egg"), etc.

The motivational signs for the semantic transformation may be taste and contents of the products, their appearance, result of consuming, cooking process, eating process, etc. The components - names of food products, while being within phraseological units, acquire both abstract and concrete meanings: хлеб ("bread") - 'home and food'; 'maintenance'; 'earnings, payment'; 'the most necessary'; каша (“porridge”) - 'mess, disorder'; 'action, including the one that is hard or unpleasant'; 'punishment'; 'life experience', etc. It has been established that the majority of phraseological units are of Russian-specific origin. Individual phraseological units got into the standard language from jargon speech. Significant number of phraseological units of literary language - both Russian and adopted - have been recorded. It is recognized that the phraseology of Russian language actively masters not only native but also adopted denominations of products. The names of the traditional Russian cuisine are predominantly the ones subjected to semantic transformation. It is the phraseological image that most frequently preserves the national specific of a phraseological unit.

Key words: national linguistic world view, phraseology, paroemia, semantic transformation, names of food.

Актуальность работы обусловлена, прежде всего, антропоцентризмом современной лингвистики, повышением интереса к проявлениям взаимосвязи языка и культуры, к моделированию национальных языковых картин мира. Фразеологические, в том числе паремиологические, фонды различных языков неоднократно становились объектом как фольклористического, так и лингвистического описания (А. Бабкин, М. Бакина, Ф. Буслаев, В. Виноградов, Ю. Гвоздарев, В. Даль, В. Жуков, Ж. Колоиз, А. Кунин, Н. Малюга, А. Мелерович, В. Мокиенко, А. Молотков, А. Мордвилко, М. Пазяк, Г. Пермяков, Л. Ройзензон, Л. Скрипник, () О. И. Гамали, 2017. 
Ю. Солодуб, В. Телия, Н. Фомина, Н. Шанский, Н. Шарманова, С. Шулежкова и мн. др.), поскольку являются, пожалуй, наиболее показательным материалом для выяснения специфики национального видения мира. Правомочным следует признать утверждение Г. Пермякова об инвариантности описываемых фразеологическими единицами (далее $\Phi Е-О . Г$.) ситуаций и вариантности знаков этих ситуаций (т. е. ФЕ, пословиц, поговорок, афоризмов) в разных языках $[4$, c. 22]. Конкретные репрезентанты ситуаций являются средством отражения обыденного сознания в образной языковой картине мира. «Ассоциации эмпирического обыденного сознания выражают сложнейший мир преломления человеческих восприятий и представлений через опыт реальной, материальной и духовной жизни народа. Оценочные представления связываются со стереотипами обыденного сознания, влияющими на восприятие мира данным этносом. Это создает удивительное переплетение общего и особенного в системах ассоциативных коннотаций одного языка в сравнении с другими» [6, с. 24]. А. Уфимцева подчеркивает, что денотативный компонент стоит на ступень ближе к объективной действительности, по сравнению с сигнификативным, обозначая видимое, слышимое, осязаемое [7, с. 106]. Именно поэтому, описывая национальные стереотипы, устойчивые ассоциации, исследователи, как правило, обращаются к цветовым, пространственным, осязательным, звуковым, обонятельным характеристикам объектов. Впечатления народов об окружающей среде моделируют, опираясь на образы растительного и животного мира, ландшафтов, климата, национальной атрибутики, элементов костюма. Наименования пищевых продуктов в составе ФЕ, ассоциации, связанные с ними, рассматривались фрагментарно [1; 4, с. 121]. Думается, отношение к пище, набор пищевых продуктов, культура их приготовления и культура трапезы являются существенным компонентом национального быта, а образы блюд - частью национальной картины мира.

Цель работы - описать специфику состава и семантической трансформации компонентов - наименований пищевых продуктов в русских ФЕ, в том числе паремиях.

Фразеологическое «меню» русского языка, выделенное более чем из 1000 фразеологических, в том числе паремиологических, контекстов, довольно разнообразно и показывает широту состава традиционной кухни: хлебобулочные изделия, напитки, закуски, 
приправы, супы, ритуально-праздничные блюда, мучные, молочные продукты, десерты. Так, в русских фразеологизмах встречаются наименования баланда, блины, ватрушка, горчица, грибы, изюм, калачи, каравай, каша, квас, кисель, клюква, ковриюка, колбаса, кофе, крендель, лапша, лепешка, лимон, мармелад, масло, мед, молоко, мясо, патока, перец, пиво, пирог, просвира, рыба, сахар и соль, сливки, сметана, сыр, уха, хлеб, хрен, чеснок, щии, яблоки, ягоды, яйца и др. Например: одного поля ягода; снимать сливки; вкушать плоды; выюжатый лимон; печь как блинь; не мед; не об одном хлебе сыты бываем; стар кот, а мясо любит; ел бы сметану, да в коровах нет талану; не осудишь и лапшииу, а прозеваешь - воду хлебаешь; погнался за ломтем, да ковригу потерял; нашла на перец горчица и т. п.

Чаще всего фиксируются наименования: хлеб, каша, сахар, масло, молоко, соль, калачи, чай, яйца, что, в целом, совпадает с набором привычных, традиционных для русской кухни продуктов. Если извлечь из ФЕ наиболее частотные наименования продуктов каждой группы, то русский «фразеологический обед» будет выглядеть следующим образом: хлеб, щзи, каша, рыба, чеснок, мед, вино.

Хлеб, как известно, всему голова, непременный атрибут и символ русского гостеприимства, обычно в соединении с солью: хлебсоль; хлеб да соль! Хлеб-соль в русском представлении - это минимальный продуктовый набор, с которого начинается и без которого невозможна любая трапеза. Это же наименование, обозначающее самое распространенное мучное изделие, может быть синонимично словам содержание, кров и пища, плата, заработок. Например: забывать хлеб-соль; отбивать хлеб; даром хлеб есть; есть чужой хлеб; хлеб насущный; на хлебах. Хлеб во фразеологическом фонде употребляется также для обозначения самого необходимого в еде - как проявления бедности, лишений: садиться на хлеб и на воду; перебиваться с хлеба на квас; хлебом не корми; и то хлеб.

Излюбленное блюдо национальной русской кухни щзи. Наименование $щ и$ использовано в целом ряде значений. В прямом как обозначение конкретного пищевого продукта: щии да каша - пища наша; чем больше жену бьешь, тем ши вкуснее; голодному Федоту и щии в охоту; красота приглядится, а щии не прихлебаются. Однако чаще наблюдается расширение семантики компонента, появление второго плана. Лексема щүи выступает в значениях 'пища', 'угощение': где щии да каша, там место наше. Поскольку щуи - основная, ○ О. И. Гамали, 2017. 
ординарная еда, их наименование служит обозначением бедности: пара липовых лещей да горшок щчей; щи да горох со щзами, да маленький горох, да большой горох и т. д., а также отсталости: лаптем щци хлебать. Щи - это блюдо многокомпонентное, а потому его наименование переносится на человеческую жизнь, межличностные и внутрисемейные отношения: своя воля во щзах. Этим элементом обозначены неприятные обстоятельства, например: (попадать) как кур во щии. Нередко этот оборот приводят как пример изменения мотивации на основе омофонии (первоначально - как кур в ощии).

Кроме того, лексема щуи становится знаком достатка, прибыли, всяческих материальных благ: для щей люди женятся, для мяса замуж идут; добрая женя да жирные щии - другого добра не ищи. Значение 'имущество', 'собственность' имеет наименование блюда в таких паремиях: голо, голо, а луковка во щи есть (т. е. нечто, не являющееся предметом первой необходимости, в хозяйстве имеется); шапка в рубль, а щи без круп (внешний лоск при отсутствии средств).

Еще один распространенный компонент - кама. Это наименование второго блюда, кушанья из сваренной крупы. Контекстуальная семантика наименования соотносима с понятием сумбурности, беспорядочности в выражениях и мыслях: каша в голове; каша во рту. В других случаях этот компонент именует любое дело (каши не сваришь - не сговоришься, не сделаешь), в том числе сложное, хлопотное или неприятное: заварить кашу; расхлебывать кашу. Этот элемент используется также для обозначения: наказания березовая каша; дать березовой каши; изношенности и ремонта (для обуви) - каши просят; жизненного опыта - мало каши съел ('молодой, неопытный') [8, с. 494].

В схожем контексте употребляется наименование продукта молоко: молоко на губах не обсохло. Молоко, как один из главных продуктов, использующихся для вскармливания младенцев, обозначает восприятие с раннего детства - всасывать с молоком $<$ матери $>$. Как и другие элементы, молоко во фразеологическом контексте имеет не единственное значение: о неудачном выстреле - за молоком; очень немногое, самое необходимое - детишкам (ребятишкам) на молочишко (о деньгах) [8, с. 603]. Наконец, компонент молоко может стать цветообозначением: кровь с молоком - 'румяный', 'здоровый'

Еще одно частотное наименование пищевых продуктов в русской фразеологии - масло. Это родовое название жировых 
веществ, изготавливаемых из растительных или животных жиров и используемых в приготовлении пищи. Масло, несомненно, важный, но не основной продукт русской кухни. Этот элемент приобретает во фразеологических контекстах такие значения: 'интерес, любопытство'- подливать масла в огонь; 'одно и то же' - масло масляное; 'удовольствие, блаженство' - как маслом по сердиу; 'богатство, довольство, достаток' - как cыр в масле кататься, заработать на хлеб с маслом; кашу маслом не испортишь; 'крайняя степень выражения' - фига с маслом [8, с. 570].

Компонент яйц̧о в ФЕ выеденное яйцฺо; носиться как курицуа с яйцом; выеденного яйца не стоит обозначает нечто не заслуживающее внимания, ничего не стоящее, пустяк [9, с. 827-828].

Россия - страна северная. Поэтому фразеологический «огород», как и стол русского крестьянина, овощами не изобилует. Среди компонентов ФЕ зафиксированы только лексемы бобы, pena, peдька. Редька - это овощ, имеющий острый вкус и запах. Компонент редька в составе ФЕ становится знаком чего-то невыносимого, очень сильно надоевшего: как горькая редька; хуже горькой редьки. А лексема репа - наименование овоща с утолщенным, округлым корнем, который очень прост в приготовлении и широко использовался в исконно русской кухне, был частым блюдом на крестьянском столе - в составе фразеологизмов приобретает значения 'нечто очень простое', 'нечто очень дешевое': проще пареной репь; дешевле пареной репь.

Таким же обычным продуктом были и бобы. Очевидно, поэтому наименование бобы означает понятия 'пустой', 'беспочвенный', 'обыденный'. Например: бобы разводить - болтать, вести пустые разговоры, заниматься пустяками; гадать на бобах - строить беспочвенные, ни на чем не основанные предположения, догадки; (оставлять (оставаться)) на бобах - оставлять без того на что рассчитывал, чего добивался, без самого необходимого [9, с. 44].

Выше говорилось о том, что, кроме лексемы хлеб, в материале встречаются наименования других мучных изделий: крендель, калач, коврижки, блины. Наименование крендель обозначает булку в форме восьмерки. По-видимому, из-за формы этот элемент ассоциируется с замысловатостью, сложностью: вылидывать кренделя - лихо, замысловато выплясывать; выдельвать <ногами > кренделя - идти неровным шагом, двигаться зигзагами [8, с. 517].

Калач - это хлеб в форме замка с дужкой. Во время приготовления () О. И. Гамали, 2017. 
этого блюда тесто долго и тщательно вымешивается. Видимо, поэтому данный компонент ассоциируется с бывалым человеком, которого трудно провести, обмануть (тертый калач) и даже с наказанием (доставаться на калачи). Калач - это вкусно, привлекательно (не заманишь калачом), у него замысловатая форма (свернуться калачом). Наконец, калач - это нечто обычное, обыкновенное (как калач испечь - легко выполнимо, ничего не стоит) [8, с. 483].

Коврижка - род пряника. Сладкой выпечкой: коврижками, пряниками (ср. также кнутом и пряником) - поощряли детей за хорошие поступки. Наименование употребляется в контексте выражения усиленного отрицания чего-либо: ни за какие коврижки 'ни при каких обстоятельствах', проявляя значение 'вознаграждение'.

Наименование блины (печь как блины - создавать что-либо быстро и в большом количестве), поскольку это сравнительный оборот, сохраняет прямое значение [8, с. 828], как и во фразеологизме к теще на блины [8, с. 26]. В обороте первый блин комом - о не совсем удачном начале чего-либо [8, с. 63] - компонент блин обозначает любое дело.

Мучные изделия готовятся из теста - вязкого вещества, из которого изготавливают продукты питания. Используется в выражениях: из одного и того же теста - 'схож с другими по образу жизни, взглядам, характеру и т. д.'; из другого теста - 'не схожий с другими'. Значение компонента тесто - 'суть, основа' [9, с. 501-502].

Перечень напитков, упоминаемых во фразеологизмах, невелик. Кроме уже упоминавшегося молока, это вино, квас, кисель, компот и чай.

Вино - синоним сил, мыслей, доходов (вливать новое вино в старые мехи - вносить новое содержание в старые формы [8, с. 145]), а также основной спиртной напиток, от которого и беда, и утешение: топить горе в вине; вино в голову ударило [8, с. 137-138]. Паремии с компонентом вино носят назидательно-констатирующий характер: вино с разумом не ладит; вино вину творит; лихому человеку вина не надобно; с вином поводишься - нагишом находишься.

Элемент кисель не имеет однозначных ассоциатов. Например, в такой единице как молочные реки $<u>$ кисельные берега, данное наименование репрезентирует привольную, обеспеченную жизнь. Во фразеологизме за семь вёрст киселя хлебать - далеко и попусту идти, ехать куда-либо - кисель - нечто привычное, обычное, что всегда есть рядом; видимо, кисель разбавляли, отсюда седьмая (десятая) вода на киселе- очень дальний родственник [8, с. 496]. 
Наименование компот заимствованное. Это напиток из сваренных на воде фруктов служит образной основой в единственном междометном фразеологизме вот так компот!, носящем просторечный характер и выражающем сложный спектр эмоций от удивления до откровенной досады.

Исконный русский напиток квас упомянут во фразеологии в виде производного прилагательного квасной. Квасной патриотизм псевдопатриотизм. Перебиваться с хлеба на квас-очень нуждаться, жить впроголодь $[8$, с. 495]. Значит, квас - самый дешевый и рядовой напиток русской кухни.

Наименование чай и его непременный «сосед» сахар в составе фразеологизмов связываются с представлением о гостеприимстве, угощении: на чашку чая; чай да сахар; за чай - caxap; на чай.

Из приправ главная - соль. Соли было мало, она была дорогой, ее экономили, поэтому пуд соли съесть - прожить долгое время вместе. Насыпать соли на (под) хвост - сделать неприятность, сильно досадить. Здесь соль - это то, что вызывает неприятные ощущения. Неприятен, горек и перец, поэтому дать периу - наказать.

Лимон не растет в России, однако вкус его плодов и способ их употребления оказались настолько впечатляющими, что название вошло в состав фразеологизмов жать лимон, выжатый лимон - о человеке, утратившем физические силы, творческие способности [4, с. 545].

Основная часть фразеологизмов исконно русского происхождения. Единичные фразеологизмы попали в литературный язык из жаргонной речи: чепуха на постном масле - то, что не заслуживает внимания, пустяк; катись колбасой - убирайся, пошел вон; баланду травить - врать, рассказывать небылицы [8, с. 31], где баланда (просторечное) - тюремная похлебка - синоним лексем ложь, небьлица.

Кроме фразеологизмов, происхождение которых связано с разговорной речью, имеется значительное количество ФЕ книжного происхождения - как русских, так и заимствованных. «Пищевые» компоненты часто приобретают в них значения, отличающиеся от значений в исконных единицах. Так, например, в заимствованных из богослужебных книг ФЕ манна (небесная) - что-либо желаемое, крайне необходимое, редкое; (запретный) плод - заманчивое, желанное, но недозволенное, запретное; соль (земли) - самое главное, важное.

Активно пополняется фразеология русского языка крылатыми выражениями литературного происхождения. Например: аттическая ( О. И. Гамали, 2017. 
соль - тонкое, изящное остроумие, шутка, насмешка; яблоко раздора повод, причина ссоры, серьёзных разногласий; колумбово яйцо остроумное решение сложной задачи, неожиданно простой выход из затруднительной ситуации; питаться акридами и диким мёдом недоедать, не иметь недостаточно пищи (акриды - это вид съедобной саранчи) и т. д.

Итак, фразеология русского языка активно осваивает не только исконные, но и заимствованные наименования продуктов.

Переосмыслению подвергаются наименования всех групп пищевых продуктов: первых, вторых блюд, приправ, напитков. Мотивационным признаком для семантической трансформации могут стать вкус и состав продуктов (постная жизнь, хрен в голову - выражение удивления, возмущения и т. д.), их внешний вид (выжатый лимон, каша в голове), результат потребления (пьяные конфеты), процесс приготовления (пива не сваришь, кашу заварить), процесс еды (каша во рту) и т. д.

Компоненты - наименования пищевых продуктов в составе фразеологизмов приобретают как абстрактные, так и конкретные значения: хлеб - 'кров и пища'; 'содержание'; 'заработок, плата'; 'самое необходимое'; каша - ‘сумбур, беспорядок'; ‘дело, в том числе сложное или неприятное'; 'наказание'; ‘жизненный опыт’; молоко 'самое необходимое'; 'первая пища человека'; 'белый цвет’; масло 'интерес, любопытство’; ‘удовольствие'; ‘богатство, достаток’ и т. д.

Семантически трансформируются преимущественно наименования традиционной для русской кухни пищи. Именно фразеологический образ чаще всего и сохраняет национальную специфику фразеологизма.

\section{Литература}

1. Гамали О. И. Наименования пищевых продуктов в контексте паремий / О. И. Гамали // Семантика слова, образа, текста : сб. науч. ст. - Архангельск : Изд-во ПГУ, 1998. - С. 31-33.

2. Даль В. И. Пословицы русского народа : сборник : в 2-х томах / В. И. Даль. М. : Художественная л-ра, 1984. - Т.1. -383 с.; Т.2. -399 с.

3. Жуков В. П. Словарь русских пословиц и поговорок / В. П. Жуков. - М. : Русский язык, 2000. -537 с.

4. Пазяк М. М. Українські прислів'я та приказки. Проблеми пареміології та пареміографії / М. М. Пазяк. - К. : Наук. думка, 1984. - 203 с.

5. Пермяков Г. Л. Основы структурной паремиологии / Г. Л. Пермяков. - М. : Наука, 1988. - 235 с.

6. Сукаленко Н. А. Отражение обыденного сознания в образной языковой картине мира : [монография] / Н. А. Сукаленко. - К. : Наук. думка, 1992. - 164 с. 
7. Уфимцева А. А. Лексическое значение / А. А. Уфимцева. - М. : Наука, 1986. -240 с.

8. Фразеологический словарь русского литературного языка : в 2 т. / под ред. проф. А. Н. Тихонова. - Т. 1. - М.: Флинта : Наука, 2004. -832 с.

9. Фразеологический словарь русского литературного языка : в 2 т. / под ред. проф. А Н. Тихонова. - Т. 2. - М. : Флинта : Наука, 2004. - 832 с.

Стаття надійшла до редакиї̈ 06.09.2017 p. 